\title{
Analyzing and Resolving Issues in Software Project Risk Management
}

\author{
Taimoor Hassan
}

*Shoaib Hassan

\begin{abstract}
In last decade the main reason for projects failure is poor management of software. But now a day's most of the organizations are focusing on software project management for making project successful. Software project management provides overall management of software from project planning phase to project execution. In software project management we also deal with risks that may occur during development of projects. In this paper we analyze risks during management of software and we resolve issues that come in software project risk management. We introduce some approaches by which we can resolve all the issues regarding software risk management. Risk management also suggests us that how we can avoid risks and if risks occur then how we can control those risks. By analyzing software risk management, we come to know that what factors affect risk management and how we can remove them. Software risk $\mathrm{m}^{1}$ anagement manages all risks efficiently and makes our project successful.
\end{abstract}

Keywords: - Risk Management, Risk identification, Risk Analysis, Risk mitigation

\section{INTRODUCTION}

Risk management is one of the important knowledge areas of software project management. But most of the organizations do not give importance to this knowledge area because risk management has lowest maturity rating as compared to other knowledge areas but it has high impact for making project successful [4]. Risk management provides all the strategies about risk handling including risk avoidance, risk prevention, risk identification, risk analysis and risk mitigation. Most of the projects have high risks and risks may occur at any time in software development process. If we want to enhance the functionality of our software, then we must deal with risks. There are many factors that make project successful and risk management is one of the greatest factors that are responsible for success of any project. Many errors that occur in software development depend upon risks. Risks occur due to many reasons including incomplete user requirements, human error, natural disaster, poor project objectives and lack of resources. One of the main reasons for creating risk is incomplete user requirements. If requirements are not completed and consistent then project will fail. Risk management is a complete process for handling risks and make project successful. It is a complete process from identifying risks to monitoring and controlling the risks. In Risk management we can also manage positive and negative risks. Positive risks are those risks that have good effect on project and negative risks

Taimoor Hassan, Department of Computer Science,

Lahore Garrison University, Lahore,

*Shoaib.hassan,COMSATS Institute of Information Technology, Sahiwal, Pakistan

taimoorhassan9@yahoo.com,

shoaib.hassan@ciitsahiwal.edu.pk 
are those risks that negative effect on project. Positive risks cause project successful and negative risks cause project failure. So our main focus is to increase positive risks and reduce negative risks. Risk management is a process that directly connects with customer satisfaction. This satisfaction is called risk utility. It will be high for those people that want high satisfaction or that are risk seekers. And in risk neutral approach we make balance between risks and potential payoff.

The paper is organized as follows. Next section we describe the methodology. Section 3 presents the results. In Section 4, we summarize our conclusion and last Section 5 represents acknowledgment and last section shows references.

\section{METHODOLOGY}

First, in this paper we discuss different aspects of software risk management. As risk management is process of removing uncertainties that may come in development of project. In risk management we firstly identify risks that may occur then we analyze those risks. After analyzing risks, we manage those risks. We analyze problems that occur in software risk management and also give valuable solution to resolve that problems. Risks are the main factors that come frequently in software project management. There are different kinds of risks that affect project management process like organizational risks, external risks and internal risks [7]. External risks mean risks that occur due to some government policies or due to any unwanted condition in country. For example, company will stop the project due to high political pressure. For resolving that kind of risks organization should recommend the project charter from high authorities of government so that organization can get maximum benefit from project. Because when project will recommend then project team will utilize all its resources without any fear to make project successful. Project should be morally and socially. It should be beneficial for society. This is another factor that should keep in mind when deal with such kind of risks. If we ignore these factors, then it will be a high chance that our project will fail. Internal risks mean risks that come due to human error, lack of resources, natural tragedy, incomplete user requirements and project complexity. Such risks cause project delay. Human error risk come when we assign tasks to a developer who does not know what should be done in project. Due to less expertise in software development human error will come. Due to that risk repute of an organization becomes bad and organization will lose its future projects. For resolving that risk organization should hire people that are domain specific and should have better software project management skills. However good developers will take more money but it is better to invest in start of project rather to lose the project. Lack of resources is also a big risk that comes in maximum software projects. Most of the organization start their projects without knowing either they have enough resources to complete this project or not. And this is the main reason for bad organization's repute. In some cases, organizations have enough resources but it is high possibility that main software developer leaves organization during project development. Another problem is bad estimation of cost. In software project management we assign some cost to any project then it may be possible that project overruns that cost. In this case project will also fail. For resolving that issue we should attach some person with main software developer so that 
if main developer leaves company then project should not stop. Secondly we should estimate cost of project accurately. Cost estimation should be based on requirements [1].

We decompose our project in many milestones and we assign cost to each milestone. When we assign cost to each milestone then it will help us to do the tasks within budget. These techniques will resolve our lack of resources related risks. Another big risk is incomplete user requirements. When requirement engineer takes requirement then it is high possibility that developer will confuse about those requirements because if requirements were written in natural language then there is a high chance of ambiguity. So requirements should be clear and complete. When we do requirement engineering of any project then it is necessary to take requirements that should complete and consistent. Consistent means that requirements should not conflict with one another. For resolving that issue organization should arrange some workshops for collecting requirements from users. Workshops will create a friendly atmosphere and user will discuss all his requirements with organization and if there is any ambiguity in any requirement then developer will directly ask from user about that requirement [3]. Second way to resolve that issue is to write the requirements in a proper standard format like software requirement specification. And as a result is failure of software project. For resolving that issue we decompose our project into small units. We assign each unit to a specific team. This approach will reduce the complexity of project. Organizational risks are those risks that may occur due to organizational policies and rules. So we should make project that fulfills organization standards. As risk management is a complete process of managing the risks so for dealing all the risks that may come in software project management we make a complete model that will handle all the issues regarding software risk management. It will also manage all the risks efficiently. When we develop any software then we avoid all the risks that may come in software management process. But if risks occur then we use a strategy for dealing with risks. Firstly we identify all the risks that occur during development of software. We write all the risks in tabular form with their description. After identification we analyze all the risks. In risk analysis we analyze which risk may occur most and which risk may occur less. We find probability of each risk in the project. Probability means we analyze how many times a risk may occur. We also find impact of each risk on the project. After analyzing impact, we multiply impact of each risk with the probability of that risk to find risk factor. So this whole process gives us total information about each risk. Based on risk analysis we determine which risk has most probability and which risk has less probability. By keeping probabilities in the mind we give priorities to all risks. Risks that have high priority will serve first and risks that have low probability will serve in the last [2]. We can represent risk analysis phase by table 1 (Risk Description). After analyzing all the risks, we move to third step of risk management which is risk mitigation. Risk mitigation is an approach by which we can reduce the scope of the risk. First we try our best to avoid risk but if risks occur then we do risk mitigation to handle with risks. In risks mitigation we do some actions to decrease the probability of risk and also its impact on the project. Risk mitigation has three approaches for managing risks.

- Avoiding Risks 
- Monitoring Risks

- Contingency Planning/Possible planning

In avoiding risk approach we make a complete project risk plan in which we define probability

\begin{tabular}{|l|l|l|l|}
\hline Risk Description & Risk Probability & Risk Impact & Factor \\
\hline
\end{tabular}
of each risk and also impact of each risk on the project [5]. The main advantage of risk plan is that we can avoid risks before occurrence. In

monitoring risk approach we monitor all the risks that were mentioned in the risk plan. We check probability of each risk and also impact of each risk on the project. Monitoring of risks will help us to manage the risks efficiently. In monitoring we also check which risk has high probability and which risk has low probability so that we can give priority to risks and then dealing risks according to their priorities.

In possible planning approach, we also find probability of each risk and do some actions for resolving risks issues as soon as possible. In possible planning phase we also make again whole the plan which includes all the details regarding risks but this plan is different from risk plan that we make in risk avoidance phase. Because in avoiding risk phase we make plan for risks that may occur in project. But in possible planning phase we make plan for the risks that occur in reality. So this whole risk management process gives us a complete path for handling risks in a better way. We can represent this risk management process by given figure1.

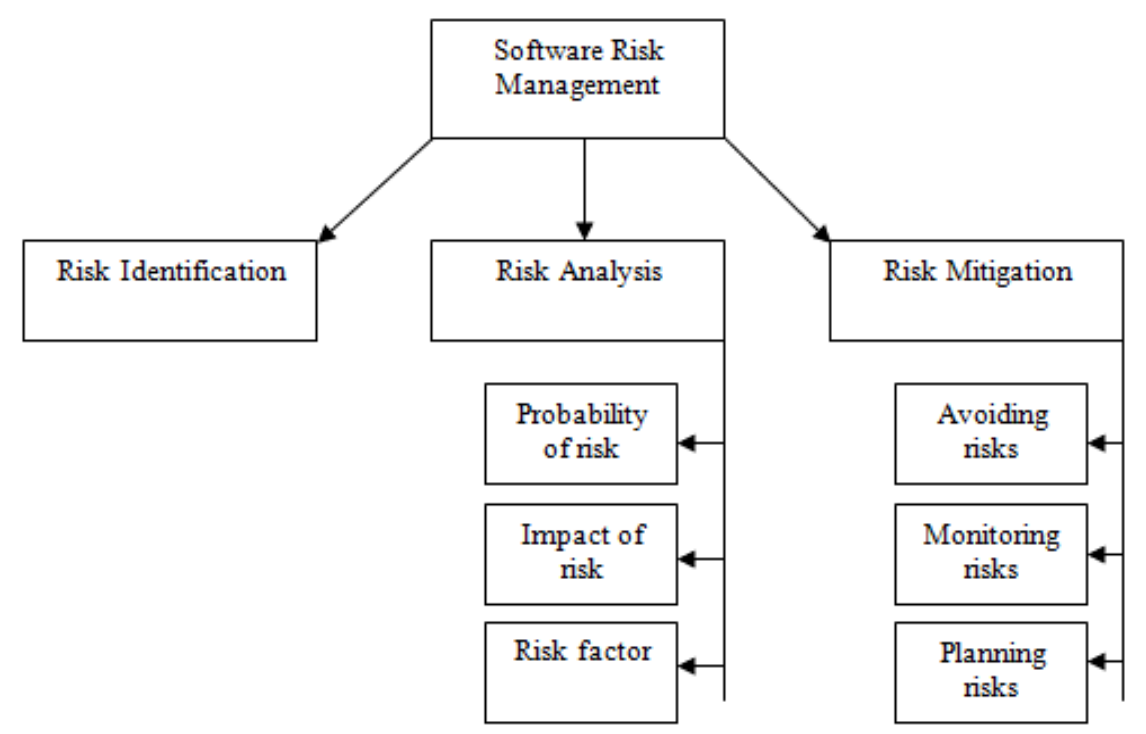

Figure 1: Software Risk Management

The overall risk description, risk probability, risk impact and overall factor are given below in table: 


\begin{tabular}{|l|c|c|c|}
\hline $\begin{array}{l}\text { External Risk (Political } \\
\text { Pressure, Safety Precautions }\end{array}$ & \multicolumn{1}{|c|}{\begin{tabular}{c} 
Table 1Risk Description \\
\hline $\begin{array}{l}\text { Product Risks (Incomplete User } \\
\text { Requirements, Lack of } \\
\text { understanding of project } \\
\text { objectives) }\end{array}$
\end{tabular}} & 0.4 & 8 \\
\hline $\begin{array}{l}\text { Process Risks (Natural disaster, } \\
\text { human error) }\end{array}$ & 0.6 & 10 & 6.2 \\
\hline $\begin{array}{l}\text { Organizational Risks } \\
\text { (Organizational Standards, } \\
\text { Organization rules and domain) }\end{array}$ & 0.2 & 6 & 1.2 \\
\hline
\end{tabular}

\section{RESULT}

Risk Management Process gives us a complete path for managing our risks in an efficient way. In risk identification phase we have complete description of our risks. Risk analysis gives us probability of each risk. It also gives us influence of each risk on the project. With the help of risk probability and risk impact we find risk factor of each risk. It also tell us which risk has highest priority and which has low priority. So with the risk analysis results we manage our risks according to priority based. Last approach which is risk mitigation reduces the scope of risk.

We use this technique when risks occur. It reduces the scope of risks. Monitoring gives us overall Description of risks probability and gives us different ways to resolve risks. We use Contingency planning only when our original plan fails. Contingency planning that also called possible planning gives us alternative plan for dealing with risks. Possible planning also has complete plan for managing risks including risk description, risk probability, risks impact and risk factor. So this whole software risk management process gives us a complete framework for managing risks in an efficient way.

\section{CONCLUSION}

After Software risk management is a framework for dealing with different kinds of risks that occur in any project. It is a complete pathway for resolving all the issues regarding risks that occur in software project. Success of any project mostly depends upon its management. If software is well managed, then there is high possibility that project will success [8]. In software project management the factor that has greatest impact on software management process is risk. So most of the organizations have focus on software risk management.

Software risk management gives us a complete strategy to avoiding risks, preventing its effect and managing those risks. It also gives us a better understanding of risks occurrences. It makes project easier and less time consuming. Software risk management reduces the complexity of project. Decisions can be taken easily based on risks. It improves overall software management process. It saves a lot of money of customer. It makes the environment of an organization risk friendly. It also maintains good repute of an organization.

\section{ACKNOWLEDGEMENT}

I would like to thanks my Allah Who gave me strength, knowledge and ability to complete this research paper and also thanks my younger brother and my wife who motivated me with their precious help and support. 


\section{REFERENCES}

[1] Risk Management System for ERP Software Project. Abbas, Dr. Muhammad, Fakhar, Muhammad Zaman and Madiha, Waris. London, UK : IEEE, 2013. Science and Information Conference. p. 6.

[2] Risk Management in Global Software Development Projects: Challenges, Solutions, and Experience. Münch, Prof. Dr. Jürgen. s.l. : IEEE, 2011. International Conference on Global Software Engineering Workshop.

[3] Collaborative Risk Management in Software Projects. Silva, Pedro Sá, Trigo, António and Varajão, João. Lisbon : IEEE, 2012. Eighth International Conference on the Quality of Information and Communications Technology. p.4.

[4] A Study Of Software Development Project Risk. Tao, Ye. Leicestershire, United Kingdom : IEEE, 2008. International Seminar on Future Information Technology and Management Engineering. p. 4.

[5] Development of software project risk management model review . Tianyin, Pu. Deng Leng : IEEE, 2011. 2nd International Conference on Artificial Intelligence. p. 4.

[6] A Model of Software Project Risk Management Based on Bayesian Networks. Tianzong, Li and Qiang, Wang. Beijing, China : s.n., 2010. International Conference on E-Business and EGovernment. p. 4.

[7] Understanding software project risk: a cluster analysis. Wallace, Linda, Keil, Mark and Rai, Arun. s.1. : ELSEVIER, 2004, Information \& Management.

[8] How Software Project Risk Affects Project Performance: An investigation of the Dimensions of Risk and an Explorator Model. Wallace, Linda. s.1. : IEEE, 2012, Decision Sciences Institute. 